\title{
Towards Learner-Oriented Monitoring and Evaluation in Adult Education Program: A Vital Approach to Ensure Adult Learners' Learning Needs
}

\author{
Yalalem Assefa \\ Department of Adult Education and Community Development, Woldia University, Woldia, Ethiopia \\ Correspondence should be addressed to Yalalem Assefa; yalalem2012@gmail.com
}

Received 15 December 2020; Revised 5 March 2021; Accepted 12 April 2021; Published 23 April 2021

Academic Editor: Lieven Verschaffel

Copyright (C) 2021 Yalalem Assefa. This is an open access article distributed under the Creative Commons Attribution License, which permits unrestricted use, distribution, and reproduction in any medium, provided the original work is properly cited.

\begin{abstract}
Monitoring and evaluation practice of adult education by its flexible nature highly needs effective and continuous professional support based on a bureaucratic system that accomplishes expectations using a hierarchical arrangement. The central essence of adult education monitoring is conceptualized as the continuous comparison of implementation progress against the predetermined principles. As well, another common vital task is evaluation. Such practice can provide formative and summative information about program implementation and outcomes for concerned stakeholders. This study placed on examining learneroriented monitoring and evaluation practices in integrated functional adult education programs. In doing so, a qualitative research approach and case study design were employed. Purposive and available sampling techniques were used to select 83 respondents. Data were collected through interviews, FGD, and document analysis. The collected data were analyzed using thematic analysis. Results showed that integrated functional adult education monitoring practice was limited to report learners' enrollment data and mere attendance in literacy class. Narrow emphasis is given to monitoring and evaluation activities that can enhance adult learners' academic performance and ability in relation to their life skills and practical learning needs have been largely forgotten.
\end{abstract}

\section{Introduction}

Modern education was introduced into Ethiopia during the first decade of the 20th century. Likewise, the beginning of modern adult education can be traced back to the same period even though it did not receive significant attention until the late 1940s [1-3]. Afterward, the development of adult education had been embracing many initiatives, for instance, the establishment of Berhaneh Zare New (literally: Your Bright is Today) Institute in 1948 [4-6] and the Ethiopian National Literacy Campaign (hereafter, NLC) in $1979[7,8]$.

Currently, the Ethiopian Education and Training Policy (hereafter, ETP) launched by the Ethiopian Ministry of Education (hereafter, MoE) emphasized the democratic, professional, coordinated, efficient, and effective educational management system [9]. The ETP has been implemented through rolling of Education Sector Development Programs (hereafter, ESDP) since 1997. A total of five ESDPs were launched by the government to improve the education system [10]. To facilitate conditions for the provision of Integrated Functional Adult Education (hereafter, IFAE) program monitoring and evaluation practice, the National Adult Education Strategy (hereafter, NAES) was endorsed during ESDP III on March 2008 [11].

A literature search showed that most of the investigated research in the field of adult education in Ethiopia focused on assessing IFAE implementation challenges and opportunities across policy and practice context, facilitators matter, and integration of IFAE into cross-cutting issues (e.g., $[1,10,12-16])$. On the other hand, this study was concentrated on demonstrating the interplay between IFAE 
and learner-oriented monitoring and evaluation (hereafter, M\&E) systems which ensures the needs of beneficiaries. The aim of this research is, therefore, to understand in depth the way regular monitoring and evaluation of adult education activities and the evolving learning needs of adult learners is done at the ground level.

This study was initiated from a discussion conducted with the North Wollo zone education department where it was found in the northeast part of Ethiopia. Woldia University and the stated zone have a memorandum of understanding to work together in the education sector. Accordingly, Adult Education and Community Development Department students of Woldia University had been assigned in different parts of North Wollo zone districts (including Woldia, Kobo, and Lalibela towns) to demonstrate their learning in two terms. The rounds had taken place from 2-25 December 2019 and 12-28 March 2020. During the time, a discussion was conducted with district education officers, facilitators, and adult learners concerning how IFAE program management and controlling practice looks like in the area. Unfortunately, it was observed that there are some gaps in monitoring and evaluating the IFAE program.

The observed gap in advance from the discussion meeting is explained by three categorized deficiencies. These are (i) utilization of key quality control indicators in monitoring IFAE progress, (ii) means to efficiently appraise IFAE performance to decide, and (iii) the timing and person(s) responsible for conducting M\&E of IFAE. Inspired by these problems, the researcher decided to make the overall $M \& E$ practice of IFAE at the grass-root level known scientifically. Therefore, this study was growing out of a preliminary overview of IFAE practice to grasp how learneroriented $M \& E$ was practiced in IFAE to ensure adult learners' learning needs. To the end, the following three research questions were set to guide the focus and direction of the study. These are the following:

(i) How have the monitoring and evaluation tasks been functional to scrutinize the relevance and responsiveness of the IFAE practice to the learning needs of adult learners?

(ii) What are the dominant factors that encounter adult education practitioners to regularly follow up the IFAE implementation progress?

1.1. Theoretical Framework. The theoretical framework of IFAE M\&E is built up with relevant literature from beneficiaries' personal, economical, and sociocultural perspectives. In due course, a sound understanding of how M\&E practices evolve and how and by which factors these are influenced allows the researcher to describe the necessary conditions which help to design, set up, and discuss relevant IFAE program M\&E practices. Over time, an extensive theoretical literature has been developed in the field of adult education [17]. So, there is a wide choice of theories available in the literature. Accordingly, the critical theory of adult education contended by Paulo Freire (1921-1997), Julius
Nyerere (1922-1999), and Jack Mezirow (1923-2014) was used, because their insight was found to be sound with this study scope.

The notion of what constitutes critical adult education theory and practice is strongly contested, partly because the word critical is open to so many interpretations [18]. According to conventional wisdom, Freire and Nyerere strongly contested that adult education must lie in humanity, thereby helping adult learners to participate in dialogue to empower themselves and critically reflect on their life situations [17, 19]. Additionally, Jack Mezirow has built a lot of standings from exploring concepts of critical reflection, transformative learning, and communicative action [19]. Mezirow argues that the overall purpose of adult education is to realize one's agency by expanding adult learners' awareness and critical reflection. The significance of this theoretical perspective concerning this study lies in the fact that adult education can be built based on employing mechanisms that help to clarify misunderstandings embedded in M\&E of IFAE approach from adult learners' need.

Even though there is little agreement on the concept of $\mathrm{M} \& \mathrm{E}$ in literature, it is a good governance instrument when planning and implementing interventions supposed to be identifiable within the framework of known theories [20, 21]. However, many of authors agreed that adult education M\&E is a combination of data collection and analysis (monitoring) and assessing to what extent a program or intervention has met its objectives or not (evaluation) [22-28]. Additionally, $M \& E$ covers a range of activities that are all ultimately aimed at ensuring the quality and continuous improvement of the teaching-learning processes of adults [21, 29].

Scholars in the field, therefore, suggested varieties of adult education M\&E theoretical models and approaches. For instance, Wagner [30] provided three models such as (1) the traditional model, based largely on census inventory to collect national and regional rates of illiteracy; (2) the largescale survey techniques employed with the International Adult Literacy Survey; and (3) an intermediate type of assessment that attempts to tailor the size and complexity of the survey methodology to the policy questions needing answers. On the other hand, Jacobs et al. [31] discoursed three approaches of adult learning monitoring such as (a) the logical framework approach which attempts to meet the needs of senior decision-makers to summarize, organize, and compare learning programs; (b) participatory monitoring and evaluation which lights the needs of field staff to work sensitively with intended beneficiaries-adult learners and support their learning and empowerment; and (c) feedback systems which appear to link the two, providing performance data for adult learning supervisors and creating encouragements for implementing staff to focus on their intended beneficiaries.

After identifying such a theoretical framework developed by scholars, the last one is chosen to be able to systematically analyse the predetermined research questions. Thus, this study took its position on Jacobs et al.'s [31] work because adult education $M \& E$ by its flexible nature and scope knocks a group of beneficiaries' learning needs and other concerned providers. The three approaches proposed 
by Jacobs et al. meet different stakeholders' needs. In general, it considers the needs of senior managers and donors of adult education. Participatory monitoring and evaluation meet the needs of adult learning supervision, facilitators, and coordinators to engage sensitively with local people and support their processes of building knowledge, skills, and confidence. Feedback systems appear to offer a way of linking both learning providers/donors and beneficiaries by providing summary data for learning administrators and creating inducements for facilitators of adult learning to focus on learners' priorities. Therefore, this study intends to position itself in the existing literature of the logical framework approach, participatory monitoring and evaluation, and feedback systems model.

IFAE program in Ethiopia is perceived as acquisition and practice of the mechanical skills of the 3Rs (reading, writing, and basic arithmetic skills), life skills (relates to basic knowledge and skills gained from agriculture, health-hygiene and sanitation, civics education, saving and related facts which are covered by the topics in the literacy program by considering the adult learners' daily life), vocational skills (relates to income generation activities such as weaving, pottery, and sheep fattening, etc.), and business skills (skills which enable to run a business such as basic bookkeeping and assessing competitors) [5, 10, 11, 32]. The NAES identified beneficiaries of the IFAE program including any individual and groups whose age is above 15 years old [11]. The strategy also emphasizes two categories of beneficiaries. The first one is individuals who previously have not got the chance to enroll in primary school. The other one is also early school leavers or individuals who did not complete their primary school $[5,11,33]$. For these categories of beneficiaries, adult education provider institutions must make delivery in their plan through continuous monitoring and evaluation of their course of action [34].

$M \& E$ is a key part of the effort to understand the effectiveness of innovations in adult learning programming and impact $[30,31]$. Therefore, practitioners during M\&E have an inherent interest in finding out how the program performed and what needs to be improved for realizing the learners' learning needs [25]. Furthermore, IFAE M\&E conceptual illustration (see Figure 1) was presented as adapted from Nafukho et al. [34]; Sava [25]; and Shechtman et al. [35].

\section{Methods}

This study was targeted at Woldia, Kobo, and Lalibela towns, which are found in the North Wollo administrative zone, Ethiopia. In conducting the study, a qualitative research approach was used $[36,37]$. Since the focus of this investigation centered on developing an in-depth investigation and analysis of learner-oriented M\&E practice in the IFAE program, case study design particularly a single instrumental case study pioneered by Creswell [37] was employed. The sample was drawn from four categories of the study population (including 6 adult education experts, 3 school supervisors, 44 facilitators, and 30 adult learners) using purposive and available sampling techniques.
Data were obtained from these respondents and the documents. Multiple instruments such as interviews, FGD, and document analysis were employed to capture needed data. Furthermore, the semistructured interview was administered for IFAE experts, supervisors, and facilitators. The main interview issues were specified in the form of an interview guideline [28]. In line with the research objectives, interview topics were structured into three major themes which means that all candidates are asked the same questions in the same order to get a nearly similar response. These are (a) coverage and extents of IFAE monitoring practice, (b) challenges influencing IFAE monitoring, and (c) status and means of IFAE evaluation. In addition to this, FGD was carried out with adult learners. The groups ranged in size from eight to twelve adult learners. It was planned to conduct five FGDs at the selected case study areas; however, data were saturated when three FGDs were done. Additionally, documented data related to IFAE M\&E was obtained to relate primary data.

Procedurally, the interview with each interviewee has lasted 30-45 minutes. Their response was recorded in audio and transcript verbatim. In doing so, i.e., collecting and reporting of the analyzed data, all respondents' confidentiality was secured through anonymity. Their name was coded (e.g., IFAE experts as E1, E2, 3, .., 6; supervisors also S1, S2, and S3; and facilitators name replaced with F1, F2, F3, ..., F44). The three FGDs points of view were communicated as FGD1, 2, and 3. Additionally, reports and proceeding documents of education office and literacy centers (hereafter, LCs) were utilized to support and strengthen the primary sourced data. The collected data were analyzed through coding and a detailed description of the case under themes using ATLAS.ti 7. A detailed description of existing case events has emerged in parallel with the data collection process. After the description, the researcher gave focus to a few problems for understanding the complexity of the investigated case. Finally, as suggested by Creswell [37], identifying issues within each case and then looking for common themes were considered. Therefore, thematic analysis was the major technique of analyzing data and interpreting the study results.

\section{Results}

3.1. Learner-Oriented Monitoring: Warranting the Track of IFAE Implementation Progress to Learners' Needs. It has been known that IFAE experts and school supervisors play a significant role in providing constructive feedback and overcoming challenges that may face program implementation progress. Frequent monitoring helps to ensure the needs of the learners. It also provides information about which decisions can be made either to improve future levels of performance or to change the initial plans of the IFAE. Adult learners are coming to LCs voluntarily to empower themselves without anybody's enforcement. The learning contents and environments around them are, therefore, carefully designed in a manner to transform their personal, economic, and sociopolitical lives. Consequently, monitoring activity passes through a process whereby the 


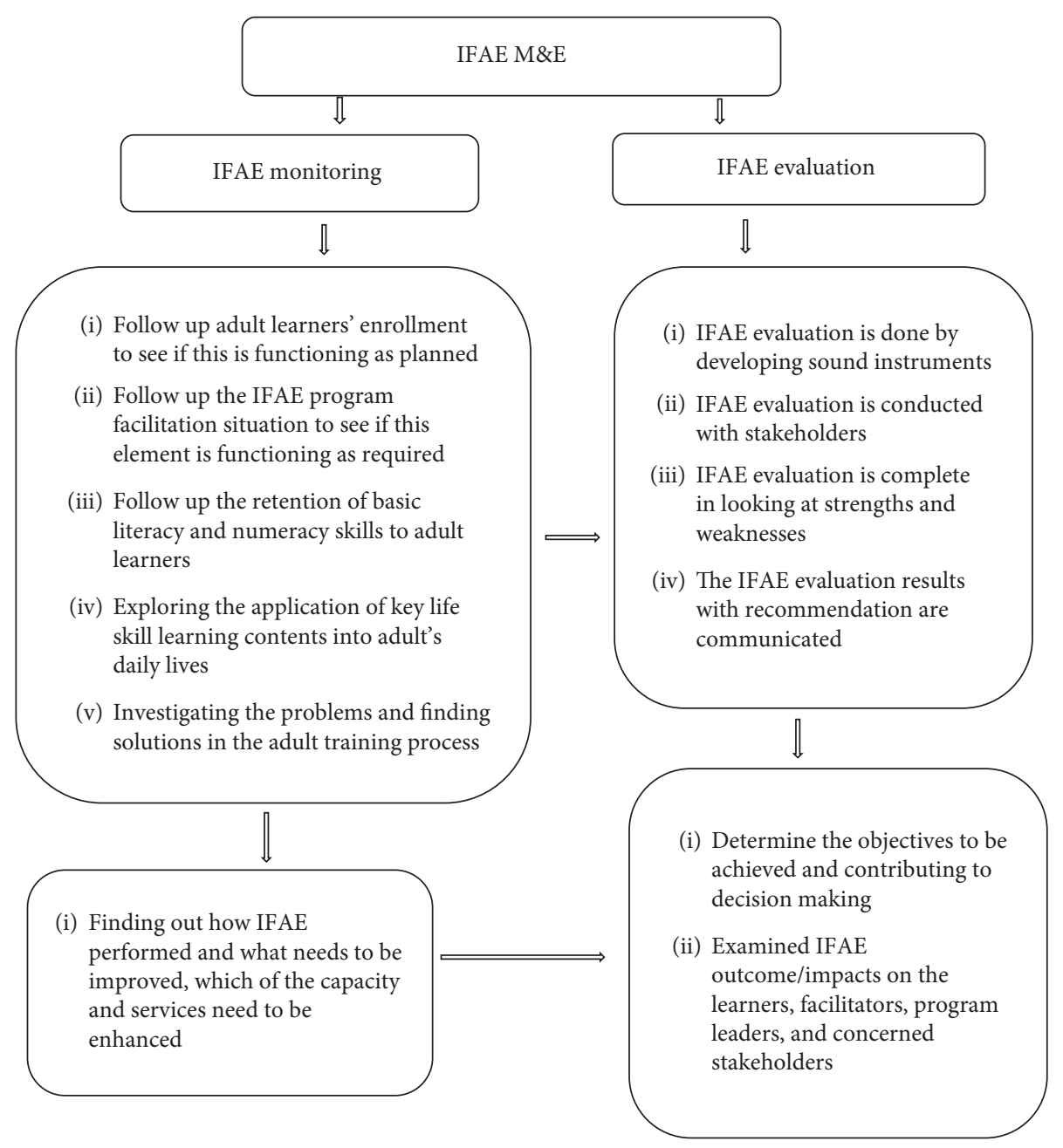

Figure 1: IFAE program M\&E.

performance levels of learners are systematically checked against their expectation levels. Monitoring, therefore, must be designed in such a way to address whether the progress of IFAE provision is in line with learners' need.

Inspired by Effective IFAE Monitoring Systems and Principles established by MoE [11, 32], the researcher forwarded a question to facilitators to focus on how monitoring processes are accomplished in line with adult education principles. The given response was categorized under four subthemes as (i) following up learners' enrollment at the LCs, (ii) surveying the IFAE program facilitation practiced by facilitators, (iii) following up the retention of literacy and numeracy skills, and (iv) exploring the application of key life skill learning contents with adults' lives.

3.1.1. Follow Up Adult Learners' Enrollment. It is known by IFAE experts and supervisors that looking at adult learners' enrollment at literacy class to see if these are functioning accordingly is one of their tasks. To discourse this, a total of forty-four facilitators were cross-examined. Given them, except for twelve respondents, the clear majority who are thirty-two supported the perspective that following up learner's participation has given high prominence task in
IFAE monitoring practice $(\mathrm{F} 1,2,3,4,5,7, \ldots, 44)$. Additionally, during an interview with supervisors, it was characterized that monitoring of IFAE mostly focuses on examining how many adult learners are registered to learn, to what extent they are enrolling in the literacy class, and reporting mere attendance in literacy class $(\mathrm{S} 2,3)$.

\subsubsection{Surveying the IFAE Facilitation Practice.} Perspectives on teaching and instruction have changed over time as they evolve depending on the prevailing ideas about how learning (facilitation, in the case of IFAE) occurs [28]. Traditional teacher-centered pedagogical concepts of teaching and learning have been widely challenged in recent decades by modern constructivist, andragogy, learner-centered, and outcome-oriented approaches [21]. The process of IFAE facilitation is more shaped through guidance. However, as confirmed by thirty-one facilitators, the role played by IFAE monitors in surveying the facilitation process at LCs was found negligible $(\mathrm{F} 1,9,11,13,15,16, \ldots, 44)$. This perspective assured that although facilitators' facilitation practice has some uneven effect on learners who have a different level of understanding, this study observed that the magnitude of examining the facilitation process was stumpy. 
Moreover, interview with adult education experts also supported this view that:

“... so far I observed IFAE facilitation practice twice at literacy class. The lesson was about the addition and subtraction of numbers. Learners' participation was imbalanced which may result from higher-ability learners are more likely to experience their learning consistently than the lower ability. Regarding this characteristic of adult learners', facilitators must adjust their facilitation to a different category of learners. However, there is a limitation from them in handling these kinds of situations, because their educational achievement was at least grade 10. They lack the basic andragogical facilitation principles even though short-term training was given. Even if experts haven't observed frequently due to constraints, I believed that giving continuous feedback would help to shape and minimize this kind of gap during facilitation" (E5).

IFAE facilitation practices are not only the result of interaction between facilitators with learners but also affected by pressures from their social environment which may result in adjusting their standards for types of learners. That is why educational monitoring is endorsed to focus on the facilitators' ability to effectively convey acceptable social conduct to their learners, as expressed in real life [38]. Therefore, all rounded monitoring across learners' needs, facilitators' potential, and learning context must be the center.

3.1.3. Examining the Retention of Literacy and Numeracy Skills. Monitoring of IFAE facilitation particularly follows up whether the retention of literacy and numeracy skills with adult learners' daily lives becomes a vital function for education personnel. To promote this more through a legal base, MoE [11] launched NAES aimed at equipping adult learners with essential literacy and numeracy skills through the IFAE program. However, the practice given to this looks minimal. Except for a few who identified the average (F19, 27 , and 31), most of the forty-one respondents discoursed that unless taking the numbers of an adult participants at LCs, experts and supervisors during their supervision did not adequately cover the retention of literacy and numeracy skills (F1-F18, F20-F26, and F28-F44). This result implies that the attention given to this function was near to the ground. Poor results of adult learners in the retention of literacy and numeracy lead to remedial activities before progressing to the next level. Monitoring in IFAE is a checkin success of instruction.

3.1.4. Exploring the Application of Key Life Skill Learning Contents to Adult Learners' Lives. The foremost goal of the IFAE program is the application of key life skill learning contents such as health education, agricultural extension, income generation activity, civics education, and environmental conservation into adult learners' daily lives [11]. Hence, continuously following up this activity must be the furthermost responsibility for concerned bodies to realize this objective. Results from cases have shown that thirtynine facilitators supported the symbolic effort given to exploring the application of life skill learning contents into adults' daily lives $(F 1,2,5, \ldots$, and 44$)$. Response from experts and supervisors also confirmed this result that due to lack of stakeholders' active participation not only in the implementation but also in monitoring of IFAE, our task was mostly restricted to assessing and reporting how many adult learners are there learning literacy and numeracy in the LCs (E1, 3, 4, and 5; S1 and 3). On the other point of learners' view in FGD, I was surprised by a learner who is 56 years old. He said,

“... Ayeh Yene Wondim [meaning: look my brother] I am getting aged... what worth me learning numbers and writing words alone? I came here to improve my skill in growing crops in my small-scale farm area using my limited resources. When I was joined this literacy class, my expectation was more even though it was far from my needs. Most of the time supervisors communicate with us about how the literacy class is going on. They did not try to see how the facilitation process treats us, which is incomplete in helping us to integrate skill-based learning contents with our life.... Why not regularly followed and helped our facilitators to fix the facilitation gap? If so, they [facilitators] can help us in a good manner and our expectation may be realized (FGD3)."

This result communicates that monitors of the program did not adequately explore the application of life skill learning with adult learners' daily life, which are considered as the outcome of the program. Unfortunately, the emphasis given to these was symbolic.

3.2. IFAE Evaluation: Designing Its Way as Learners-Based. While evaluating all aspects of educational services, there could be an agreed-upon procedure for recording, reviewing, communicating, and building on the results of the evaluation $[25,38,39]$. Likewise, IFAE program evaluation must be accurate. Its accuracy is measured by the methods and process is followed. In the same manner with this study perspective, IFAE facilitators were invited to deal with the way how evaluators evaluate the program (see Figure 2).

3.2.1. Defining and Designing Evaluation Instruments. Indeed, the utilization of instruments in evaluation has a great potential to collect all-rounded performance information. This in turn helps to determine the magnitude of program output/result. The accuracy of IFAE program evaluation more depends on the instrument used by evaluators. So, selecting and using relevant evaluation instruments help to discover significant, sessional, and secure information for making a productive decision about how beneficiaries are influenced by the program. Therefore, as indicated in Figure 3, of the total of forty-four interviewed facilitators, three-fourths (75\%) of them supported the satisfactory level of instrument utilization such as 


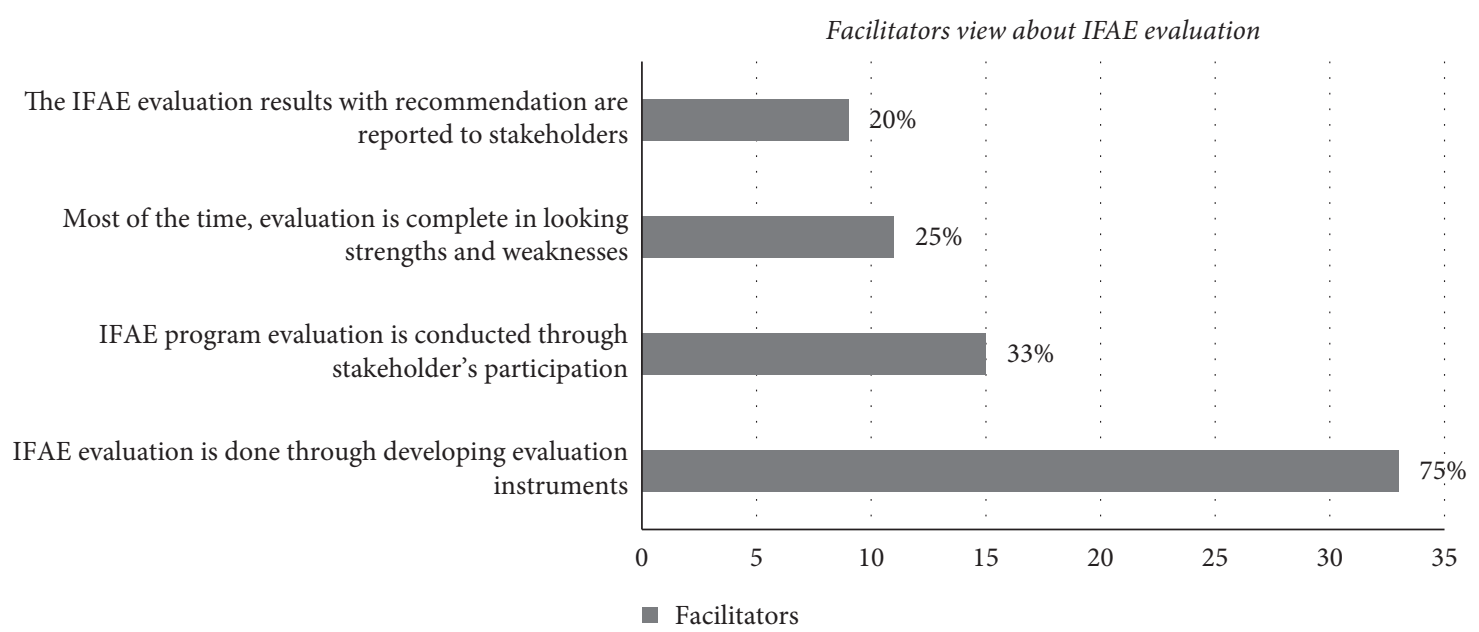

FIgURE 2: IFAE evaluation.

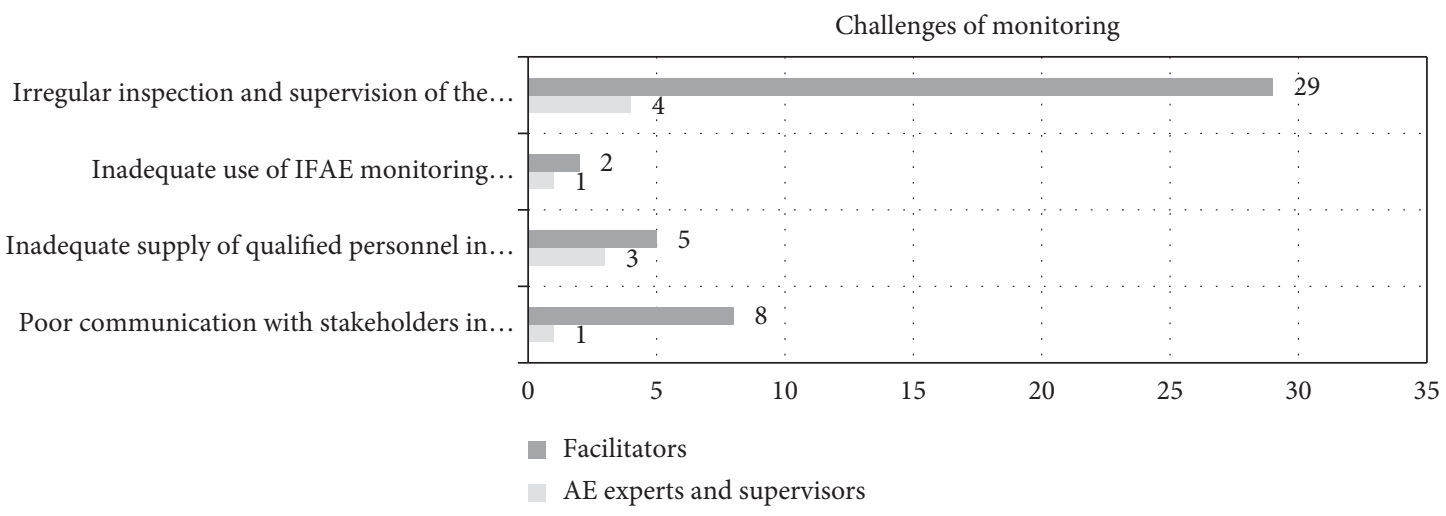

Figure 3: Major challenges of IFAE following up.

observations and questioning and answering used during evaluation (F1, 2, 3, .., 44). Furthermore, experts assured that, before evaluating the IFAE progress and performance, first, we develop instruments such as checklists, interviews, questionnaires, and FGD guiding questions with concern (E2, 3, 4, and 6).

Interview dealing with supervisors also support this result as "IFAE evaluation are conducted through employing prepared questionnaire checklists, interviews with LCs coordinators and facilitators, and sometimes making FGD with learners" (S3). However, adult learners during FGD were unsatisfied with the appropriateness of instruments used (e.g., FGD 2 and 3). To scale up this result, previous documentation showed that, even though many of the questions have been written in the questionnaire, its design was bounded to ask learners about their level of participation and satisfaction from IFAE. The instruments do not inspire evaluators to examine furthermore about how participation in IFAE affected adult learners' daily lives.
3.2.2. Stakeholders' Participation in IFAE Evaluation. The evaluation report/information collected through stakeholders' participation enables them to make accurate and tangible decisions about the program. Researchers in the field of education noticed the important role of stakeholders' collaboration in provision and performance assessment [25, 28, 40-42]. Regarding this, two-thirds of respondents (66\%) revealed the minimal efforts of stakeholders' participation played in IFAE program evaluation $(\mathrm{F} 1,3 \ldots 42$, and 44). However, $33 \%$ have good looking at this. Interview with supervisors also supported this result that even though we have relative cooperation in working and sharing some practices in the formal education settings, collaboration given to IFAE which is delivered in a nonformal base is emblematic ( 1 1 and S2). It is best when the organizer, management committees, and all other concerned stakeholders are involved together in the IFAE program evaluation activities. However, this study result implies that the participation of the concerned LCs stakeholders is near to the ground. 
All evaluations invited them to provide feedback about how facilitated learning changes their survival [40]. Moreover, from FGD it was understood that learners are eager to share their opinions about how they need their learning and could be improved to enhance their lives, which they regarded as the purpose and intended use of evaluation. Adult learners, facilitators, the local community, etc. must actively be involved in IFAE program evaluation. However, from practical experience, it is observed that all concerned stakeholdes' limited involvement in the IFAE program created a deficiency to assess results, outcomes, and its impact on beneficiaries.

3.2.3. Evaluation Feedback Conveyance. It is a fact that evaluation at any institution must be holistic in promoting outstanding achievements and addressing all observable shortcomings. Unexcitingly observed in Figure 3, the result of this study shows that three-fourths (75\%) of facilitators pronounced the negligible level of evaluation that was carried out at the LCs which lacks full examination of what strength and weakness the LCs have (F1, 3, ., 44). IFAE evaluators must assess the total performance across its working context as defined by the NAES, governments, and LCs course of action. In the end, dissemination of evaluation reports for IFAE stakeholders has a great value to share the strong and weak performance/result about the program. Unfortunately, only $20 \%$ of facilitators confirmed the extent of the report disseminated to them continuously (F3, 5, 9, .., 44).

On the other hand, evaluation feedback inspired IFAE achievement following course plans and changes in performance. However, the majority, i.e., $80 \%$ of respondents, emphasized that experts' and supervisors' evaluation reports seldom provide the way forward $(\mathrm{F} 1,6,7, \ldots, 43)$. This result tells whatever the evaluation results obtained from LCs, distributing evaluation reports for stakeholders was found meaningfully low. The evaluation of IFAE in the decisionmaking process and determining of new plans, evaluation report appeared to be compatible with the need of adult learners aimed at further improvement through the feedback system.

\subsection{Challenges of IFAE Following Up: Limiting of Potentials for} Monitoring and Evaluation. IFAE monitoring practices are not only shaped by monitors' beliefs on how facilitationlearning happens but are also affected by several factors [28]. To define the scope of IFAE monitoring, adult education experts, supervisors, and facilitators were asked: what kind of challenges available are negatively affecting IFAE monitoring? They identified many confrontations. To make sound analysis, the researcher categorized all the raised challenges under four subthemes based on their resemblance (see Figure 3).

3.3.1. Poor Communication. Enhancing open communication in the process of conducting IFAE monitoring has a positive impact on concerned bodies' course of action and decision-making capacity. It also stimulates LCs' effectiveness in the provision of educational opportunities for adult learners according to their needs. Eight facilitators and one expert (see Figure 2) portrayed the availability of poor communication among stakeholders (F5, 8, 9, 17, 24, 25, 31, 40, E2). From FGD with adult learners, it was frequently pronounced that learners at LCs are learning many learning contents selected from health, agriculture, civics, and others. Likewise, facilitators are drawn from such sectors. However, they are not well coordinated in their service delivery. Hence, developing a sense of working together must be at the center of this program (FGD1). This result tells the existence of reservation despite communication and sharing of diversified perspectives has the power of creating a common understanding and sense of ownership in monitoring.

3.3.2. Lack of Well-Suited Personnel. Qualified practitioners' role is indispensable in the monitoring of educational programs when establishing a school-wide culture concerning assessment [28]. On the contrary, eight respondents $(\mathrm{F} 2,12, \ldots, \mathrm{E} 1, \mathrm{~S} 1$, and E5) exposed an inadequate supply of qualified personnel who are responsible for pattern and provide feedback for IFAE implementation progress. Fortunately, there are more than nine higher learning institutions-universities in Ethiopia that started producing graduates of adult education and community development professionals in undergraduate and postgraduate programs. Researchers suggested that the public service in collaboration with MoE needs to put a new structure that absorbs this graduate which may be an input for both monitoring and successful realization of the IFAE program [43].

\subsubsection{Inadequate Use of Monitoring Instruments and Ir-} regular Supervision. Practitioners are required to develop and utilize the relevant instrument to collect the needed information about the issues to be monitored before starting their job. Even though there is a shortage of professionals in IFAE, three respondents stated that the available experts did not use adequate monitoring instruments (F35, 43, S3). Along with the widely supported amalgamation of monitoring practice that meets the needs of adult learners, it is essential to make it seasonal and regular. Nevertheless, twenty-nine respondents of the case study disclosed the presence of irregular inspection and supervision of the IFAE program (F1, 3, 4, .., F 44, S2, E3, 4, 5, and 6). This result is consistent with a previous study which was studied in eastern Ethiopia conducted by [43]. They revealed that absence of trained, reasonably paid, dedicated, and committed experts to manage and coordinate the programs made the expected technical support unseasonal and more complicated.

\section{Discussion}

The central essence of monitoring is conceptualized as the continuous comparison of actual progress against the predetermined indicators, which was in the IFAE plan $[25,30]$. Regular monitoring of adult education activities and the 
evolving learning needs of the affected population is vital to ensure the safety and security of all learners, facilitators, and other personnel. This is because it helps to (a) ensure that monitoring interventions are relevant and responsive to beneficiaries' need; (b) identify possibilities which demand improvement; and (c) promote accountability. Nevertheless, this study showed the unsatisfactory level of IFAE monitoring practice conducted at LCs. This may be because less attention is paid to the soundness of defining and classifying adult learning activities that are to be monitored. Even the data collected may become less meaningful and potentially less applicable at the ground level.

It is a fact that a bureaucratic system accomplishes expectations utilizing a hierarchical arrangement, based on a supervisory relationship between supervisors and supervisees [44]. IFAE by its flexibility in nature highly needs effective and continuous professional support. Therefore, it is argued that continuously monitoring and supervising the IFAE program helps to sustain the success and take corrective action if some challenging factors may appear during the program implementation process. However, the result proves that the extent of IFAE monitoring delivery for all LCs was insufficient and at the same time imbalanced. The coverage of IFAE program monitoring in this study was more limited to see adult learners' enrollment.

Wagner [30] suggested two important questions that need to be answered by practitioners while undertaking further IFAE monitoring: (a) what do adult learners know in terms of key learning skills and (b) how are these skills used in their lives? However, as compared to the practice with the knowledge and skills that need to be acquired by adults across every aspect of their lives framed by [35] and the IFAE monitoring frameworks $[11,32]$, this study discoursed the narrow emphasis given to examine the core elements of IFAE programs such as surveying the facilitation practice, following up the retention of literacy and numeracy skills into adult learners' daily life, and exploring the application of key life skill learning contents into adult learners' daily lives.

Typically, IFAE monitoring focuses on the inputs in human and infrastructural resources, the andragogical methods employed, and the outcomes in terms of attendance and successful program completion [30]. A lack of skillbased support-based follow-up is typically a very serious gap observed in the IFAE program monitoring knowledge base.

Scholars gave a sense to IFAE monitoring as it is the continual process of collecting and analyzing data to determine if an initiative is going on in a way that achieves its intended results [34]. However, inadequate use of monitoring instruments, poor communication, and discussion among stakeholders highly affects its process. The monitoring of the IFAE program interacts with all the other parts of the IFAE program from its preplanning stage throughout its implementation and conclusion.

Moreover, it is unquestionable that adult education personnel during monitoring of the program have an inherent interest in finding out how the program performed and what needs to be improved and which of the organizational capacities and services need to be enhanced [25]. Nevertheless, the inadequate supply of qualified personnel who could provide productive feedback is the main factor that challenges monitoring of the IFAE program continuously in the study areas. This was in parallel with the previous concluded study of inefficient andragogical monitoring skills in most IFAE centers [43].

Another common controlling purpose of the IFAE program is to inform evaluation and practice improvement. Evaluation in its specific form in IFAE should be regarded as an assessment or judgment of a circumstance about program effectiveness based on information. The information is gathered, analyzed, and assessed for a specific end to decide on program implementation and outcomes [29, 35]. In support of this view, Saitis and Saiti [38] pointed out that IFAE evaluation assists in (1) presenting all data that the adult LCs have evaluated including the entire educational system to improve where necessary; (2) ascertaining the quality of structures and functions as well as the outcomes of their teaching work; (3) disseminating good practices to other parts and supporting teaching staff during the process of acquiring additional training and receiving feedback after completion. During an evaluation of the IFAE program, evaluators develop evaluation instruments (including checklists, interviews, questionnaires, and FGD). This is a good habit because evaluation data gained from every step of the evaluation process through a variety of instruments can provide formative and summative information about the program implementation and its outcome for facilitators, program leaders, funders, and other concerned stakeholders $[21,35]$.

Previous literature demonstrated that all-around IFAE $\mathrm{M} \& \mathrm{E}$ is conducted when a range of stakeholders are involved [22, 31, 45]. A well-designed evaluation demonstrates its usefulness (gathering data in time and communicating with stakeholders), feasibility (realistic and adequate to the context of the program), propriety (respecting ethical and confidential issues), and accuracy (using objective and welldefined standards) [25] when all actors are involved. In this study, however, it was found that most of the time IFAE program evaluation was undertaken by education experts. Other involvement was at the ground. Using a group of stakeholders enables bringing new inventiveness and presenting a new effort in the IFAE program which highly requires the involvement of different sectors. Participant involvement in the evaluation process can contribute to establishing a sense of ownership over the program. It also increases the relevance of evaluation questions, which in turn might affect the use of the subsequent data. Participation in the IFAE evaluation is significant to ensure stakeholders' accountability [44]. More dialogue between evaluators and adult learners' involvement in evaluation processes can be taken as keys to achieving the objective of evaluation stated in the internal quality assurance system where learners' evaluation is regarded as part of their learning processes [40].

According to Lattke [21], evaluation in the field of adult learning may be applied to a broad range of objects. These include a single course or learning offer as a whole; the learning process, progress, and outcomes of individual learners; the professional performance of the teacher, 
trainer, or facilitator; the total offerings of an adult learning provider; the management systems and structures implemented in a provider institution. This study revealed evaluation in adult education focused in detail on a review of principles and policies, organization and resources, the effectiveness of facilitation, and satisfaction of learners with strength and weakness. However, the evaluation practice lacks a detailed examination of what strengths and weaknesses the LCs have.

This study is in consort with previous studies that recognized that IFAE evaluation reports have a multipurpose tool that aims to improve and assure educational quality, improved facilitation, and adult learning, which is central to educational enhancement. However, the use of evaluation reported data for these purposes is less robust than expected $[20,26,40]$. The extent of distributing IFAE evaluation results report for stakeholders to discuss and share the strengths and weaknesses needs improvement. There is disclosed existence of good practice in reporting the evaluation results along with recommendations to LCs. This ought to be scaled up to others.

\section{Conclusion}

This study discoursed the attention given for IFAE program monitoring and evaluation was more limited to see adult learners' enrollment, i.e., how many adults are registered and attended the literacy class at their nearby. Monitoring and evaluating the core elements activities of IFAE that can enhance adult learners' academic performance and ability in relation to their life skills and practical learning needs have been largely forgotten. This is resulted from inadequate use of monitoring instruments, poor communication among stakeholders, and an inadequate supply of qualified personnel who could provide productive feedback. The conditions that are reflected in the presence of many hindering factors, therefore, cannot ascertain the relevance and responsiveness of the IFAE practice for beneficiaries.

The evaluation process was designed to aim to appraise IFAE progress; satisfactory performance and impacts on learners are enhanced through a variety of instruments. Stakeholders' participation in the IFAE program evaluation was significant to ensure stakeholders' accountability, yet its practice was found on the ground. There are observed limitations in critical search of what good practices and outcomes should be expanded to others, and which further improvement measures are needed to solve faintness.

\section{Implication}

The following suggestions are forwarded:

(1) The study result showed that during IFAE program monitoring more emphasis was given to look at how many adult learners are registered and enrolled in the LCs. But this should not become the only main objective of IFAE program monitoring. Therefore, during monitoring of the program carried out by concerned stakeholders' monitors, more emphasis must be given to examining the retention and application of basic literacy skills and the integration of life skill learning contents into adult learners' daily life through creating a strong system of continuous follow-up. The main assumption and objectives of the IFAE program lie in between these facts.

(2) Individuals who are actively involved in the monitoring and evaluation of the IFAE program determine the program's success or failure. Primarily, they must carefully give enough consideration to the learners and all beneficiaries' interests through the program. Then, it is important to design leading inquiries such as what core activities to be monitored and evaluated, what questions to be answered, the instruments to be employed in collecting data, and how the monitoring and evaluation results, as well as reports, will be distributed for all concerned bodies.

(3) Evaluation results and reports have great worth to make all rounded decisions concerning the provision of the IFAL program. However, the study displayed evaluation that lacks a detailed examination of what the LCs have and dissemination of reports for all concerned bodies. This may lead to misunderstanding and miscommunication among providers, funders, and beneficiaries about the program result. The program evaluators are responsible to look at carefully the actual performance through examining the strengths and weaknesses of IFAE practice critically. Evaluation results could be disseminated through reports and meetings with concerned stakeholders to make decisions aimed at whether to appreciate and sustain the current results or to take a lesson learned for the future course of action.

\section{Data Availability}

All data collected and anayzed during this study as well as associated with it are available from the author and will be available upon your request.

\section{Conflicts of Interest}

The author declares no conflicts of interest.

\section{References}

[1] W. Dessu, "Peace education: a missing link in the adult education sub-sector of Ethiopia?" Ethiopian Journal of the Social Sciences and Humanities, vol. 14, no. 1, pp. 31-52, 2018.

[2] T. Seyoum, "Education and development in Ethiopia," Ethiopian Economic Association, vol. 8, no. 2, pp. 18-35, 2005.

[3] A. Sisay, "The historic move, contemporary challenges. And opportunities in Ethiopian education," International Journal of African and Asian Studies, vol. 26, pp. 56-66, 2016.

[4] K. Ambissa, "Adult basic literacy "initiatives" in Ethiopia: change and continuity," Journal for Critical Education Policy Studies, vol. 12, no. 1, pp. 238-261, 2014.

[5] B. Sandhaas, Portrait Adult Education Ethiopiadvv International, Addis Ababa, Ethiopia, 2009. 
[6] T. Workineh and W. Tilahun, "Ethiopian pioneering in adult education," Ethiopian Journal of Education, vol. XII, no. 2, pp. 36-87, 1991.

[7] Margareta and R. Sjostrom, How Do You Spell Development? A Study of a Literacy Campaign in Ethiopia [Motala Grafiska] Scandinavian Institute of African Studies, Upsala, Africa, 1983, https://search.ebscohost.com/login.aspx?direct=true\& $\mathrm{db}=\mathrm{s} 3 \mathrm{~h} \& \mathrm{AN}=58639801$ \&site $=$ ehost-live\&scope $=$ site.

[8] W. Zelleke, The Legal Basis of Adult Education: Legislation, pp. 139-157, Adult Education and Development, DVV International, Addis Ababa, Ethiopia, 2005.

[9] MoE, Education and Training Policy, George Printing Press, Washington, DC, USA, 1994.

[10] G. Genet, "An assessment of Ethiopia's progress towards attaining integrated functional adult literacy," Bahir Dar Journal of Education, vol. 14, no. 2, pp. 14-28, 2014.

[11] MoE, National Adult Education Strategy, Ministry of Education, Delhi, India, 2008.

[12] M. Abiy, A. Roger, and Z. Turuwark, "Leaving the job half done? An analysis of mid-term withdrawals by facilitators in some adult literacy learning programs," International Journal of Educational Development, vol. 65, pp. 194-206, 2019.

[13] S. Kebede and H. Muhamedhusen, "The practices of integrated functional adult literacy program in Ethiopia: the case of oromia," International Journal of Innovative Research and Development, vol. 5, no. 9, pp. 128-133, 2016.

[14] D. Samuel, G. Gelana, and D. Mekonnen, "Developing a lifelong learning system in Ethiopia: contextual considerations and propositions," International Review of Education, vol. 60, no. 5, pp. 639-660, 2014.

[15] Z. Turuwark, A. Rogers, and N. Tolera, "Profiling adult literacy facilitators in development contexts: an ethnographic study in Ethiopia," International Review of Education, vol. 64, no. 1, pp. 9-30, 2018.

[16] S. Yilfashewa and B. Garkebo, "Andragogical methods to sustain quality adult education in Ethiopia," International Journal of Instruction, vol. 10, no. 3, pp. 47-62, 2017.

[17] W. Dessu, "Adult education in Germany and Ethiopia: a comparative perspective," The Ethiopian Journal of Education, vol. XXXIX, no. 1, pp. 117-148, 2019.

[18] S. Brookfiel, "Critical adult education theory: traditions and influences," in The Palgrave International Handbook on Adult and Lifelong Education and Learning, M. Milana, S. Webb, J. Holford, R. Waller, and P. Jarvis, Eds., pp. 53-74, Palgrave Macmillan, London, UK, 2017.

[19] B. Findsen, "Freirean philosophy and pedagogy in the adult education context: the case of older adults' learning," Studies in Philosophy and Education, vol. 26, no. 6, pp. 545-559, 2007.

[20] V. Kanyamuna and M. Phiri, "Who said monitoring and evaluation is not rooted in firm theoretical foundations? A review of relevant literature," International Journal of $\mathrm{Hu}$ manities, Art and Social Studies, vol. 1, no. 4, pp. 1-23, 2019.

[21] S. Lattke, Professional Competence in Designing, Monitoring, and Evaluation of Adult Learning Processes, Erasmus+ Strategic Partnership, Bonne, Germany, 2018.

[22] A. Borkowsky, Monitoring Adult Learning Policies: A Theoretical Framework And Indicators, Organisation for Economic Co-operation and Development, Paris, France, 2013.

[23] L. Gadsby, S. Middleton, and C. Whitaker, Monitoring and Assessment in Community-Based Adult Literacy Programs in British Columbia, Ministry of Advanced Education by Literacy BC and Literacy Now, Regina, Canada, 2007.

[24] C. Lusthaus, M. Adrien, and M. Perstinger, "Capacity development: definitions, issues, and implications for planning, monitoring and evaluation," Universalia Occasional Paper, vol. 35, pp. 1-21, 1999.

[25] S. Sava, Needs Analysis and Programme Planning in Adult Education Barbara, Barbara Budrich Publishers, Opladen, Germany, 2012.

[26] V. Scherman and W. Fraser, "Monitoring and school selfevaluation: examples of and implications for South Africa," Monitoring the Quality of Education in Schools, vol. 2003, pp. 53-74, 2017.

[27] G. Skedsmo and S. G. Huber, "Policies and practices related to student assessment and learning outcomes-combining different purposes and ideals," Educational Assessment, Evaluation and Accountability, vol. 29, no. 3, pp. 225-228, 2017.

[28] J. Ysenbaert, M. Houtte, and P. Avermaet, "Assessment policies and practices in contexts of diversity: unraveling the tensions," Education for All Global Monitoring Report 2006, Literacy for Life, vol. 32, pp. 107-126, 2020.

[29] B. Basheka and A. Byamugisha, "The state of Monitoring and Evaluation (M\&E) as a discipline in Africa: from infancy to adulthood?" African Journal of Public Affairs, vol. 8, no. 3, pp. 75-95, 2015.

[30] D. A. Wagner, "Adult literacy: monitoring and evaluation for practice and policy," International Review of Education, vol. 54, no. 5-6, pp. 651-672, 2008.

[31] A. Jacobs, C. Barnett, and R. Ponsford, "Three approaches to monitoring: feedback systems, participatory monitoring, and evaluation and logical frameworks," IDS Bulletin, vol. 41, no. 6, 2010.

[32] MoE, National Report on the Development and State of the Art of Adult Learning and Education (ALE), Ministry of Education, Delhi, India, 2008.

[33] W. Dessu, "Provision and participants of adult education: an overview," Adult Education and Development, vol. 22, no. 1, pp. 196-210, 2005.

[34] F. M. Nafukho, N. Were Wawire, and P. M. K. Lam, Management of Adult Education Organisations in Africa, UNESCO Institute of Learning, Hamburg, Germany, 2010.

[35] N. Shechtman, L. Yarnall, R. Stites, and B. Cheng, Empowering Adults to Thrive at Work: Personal Success Skills for 21st Century Jobs, Joyce Foundation, Chicago, CL, USA, 2016.

[36] L. Cohen, L. Manion, and K. R. B. Morrison, Research Methods in Education, Routledge, Milton, UK, 6 edition, 2007.

[37] J. Creswell, Qualitative Inquiry and Research Design: Choosing Among Five Approaches, SAGE publishing, Thousand Oaks, CF, USA, 4 edition, 2018.

[38] C. Saitis and A. Saiti, Initiation of Educators into Educational Management Secrets, Springer International Publishing, Berlin, Germany, 2018.

[39] G. Skedsmo and S. G. Huber, "Measuring teaching quality: some key issues," Educational Assessment, Evaluation and Accountability, vol. 31, no. 2, pp. 151-153, 2019.

[40] I. Borch, R. Sandvoll, and T. Risør, "Discrepancies in purposes of student course evaluations: what does it mean to be "satisfied"?" Educational Assessment, Evaluation and Accountability, vol. 32, no. 1, pp. 83-102, 2020.

[41] C. Deluca, D. Lapointe-mcewan, and U. Luhanga, "Teacher assessment literacy: a review of international standards and measures," Educational Assessment, Evaluation, and Accountability, vol. 28, no. 3, 2015.

[42] A. Grotlüschen, B. Nienkemper, and C. Duncker-Euringer, "International assessment of low reading proficiency in the adult population: a question of components or lower rungs?" International Review of Education, vol. 66, no. 2-3, 2020. 
[43] A. Sisay and S. Yilfashewa, "Integrated functional adult literacy: existing practices and challenges in eastern Ethiopia," International Journal of Education and Literacy Studies, vol. 5, no. 4 , p. 86, 2017.

[44] G. Skedsmo and S. G. Huber, "Forms and practices of accountability in education," Educational Assessment, Evaluation and Accountability, vol. 31, no. 3, pp. 251-255, 2019.

[45] E. Vera-Toscano and C. Urzì Brancati, Towards an improved adult learning monitoring framework: revisiting the available data and indicators, Publications Office of the European Union, Luxembourg, 2020. 